\title{
Staphylococcus warneri
}

National Cancer Institute

\section{Source}

National Cancer Institute. Staphylococcus warneri. NCI Thesaurus. Code C86774.

A species of facultatively anaerobic, Gram positive, cocci shaped bacteria in the phylum

Firmicutes. This species is positive for catalase and urease and negative for oxidase,

alkaline phosphatase and coagulase. It can ferment glucose, trehalose, sucrose,

fructose, and maltose, but not xylitol, xylose, arabinose, mannose, lactose, turanose or

cellobiose. S. warneri is a commensal organism on the skin of humans and animals and is a rare human pathogen that can cause a variety of opportunistic infections. 